\title{
Design and Fabrication of Twisted Potato Crisps Maker
}

\author{
Atul Anand Mishra, Jyoti Jain, R.N.Shukla, Parvinder Kaur and Vivekanand \\ Department of Food Process Engineering, Sam Higginbottom Institute of Agriculture Technology and Sciences, \\ Allahabad 211007 (UP), India
}

\begin{abstract}
The paper describes the design and fabrication of twisted potato crisps maker. A twisted potato crisps maker is described herein comprising a base support having a first end and a second end for providing guided linear longitudinal motion along the base, longitudinal stud connecting to handle to manually rotate the stud, having a thread pitch of 13 triangular threads per inch, cutting blade which was made perpendicular to potato rotational axis and had a hole through which guide pin extended to provide support for potato, clipper, guide pin, nuts, support legs and framework. The combination of rotary and longitudinal motion produced by handle resulted in slicing of potato. This manually operated machine was designed to cut whole raw potatoes into consistent twisted crisps of thickness $2.0 \mathrm{~mm}$ approximately, suitable for frying as potato chips. The capacity of machine was $9.6 \mathrm{~kg}$ of potato per hour, and product loss was around $4.1 \%$. Locally and easily available materials like cast iron, mild steel and stainless steel were used for the fabrication. This machine allows in its simplicity of design and modest cost with the ability to generate thin uniform slices utilizing approximately $95 \%$ of the potatoes.
\end{abstract}

Keywords: Crisps, Design, Fabrication, Potato.

\section{Introduction}

Potato (Solanum tuberosum) is a starchy, tuberous crop of the Solanaceae family, semi perishable in nature, contains about $80 \%$ water and $20 \%$ dry matter. Potato is popularly known as 'The king of vegetables', because the dry matter, edible energy and edible protein content of potato makes it nutritionally superior vegetable as well as staple food not only in our country but also throughout the world. It is cultivated in 23 states in India. During 1993-2020, demand for potato is expected to rise by 40 per cent worldwide. This indicates a clear opportunity to capture the huge domestic and international market of potato by producing value added potato products.

It is estimated that $25 \%$ of the potatoes, which are spoiled due to various reasons such as lack of post harvest management, transportation, type of packing, non-availability of cold storage capacities during harvesting season, glut in the market etc., could be saved by making various preserved potato products. Processing of potato is very advantageous because it makes storage easier due to the reduction in bulkiness and due to increase in its shelf life. It adds value to potatoes and therefore gives better return. Therefore processing has been an integral part of the utilization.

The simplest mode of processing the potato tuber is conversion into chips. Potato slicing machines are either manually or electrically powered. In any of the cases, the machine consists of a knife or set of knives arranged in a particular pattern to meet the need of the operations it is intended to perform. In the former method, process is tedious and time consuming, while in the later method, equipments save cutting time but the cost of these equipments, the energy required for their operation \& their large size makes them insignificant for their use in small scale industries. Improved processing requires use of tools and techniques that are reliable, efficient, labor saving, safe, simple, and cost effective. The twisted potato slicing machine is simple workable and efficient machine, which can be adopted to reduce mechanical energy input in potato processing and also to improve product quality.

The main emphasizes was upon the design and fabrication of a twisted potato crisps maker which is cost effective as well as require less space for its functioning. Such a machine is particularly useful for small scale application.

\section{Materials and Methods}

The machine was designed to cut whole raw potatoes into consistent spiral slices, thickness suitable for frying as a potato crisps. The resultant continuous spiral sliced potato was accumulated at a position behind the blade holder for safe pick up and for frying as potato crisps.

\footnotetext{
Machine design:

The following design criteria were used:

i. Local availability and cost of material
} 
ii. Mechanical properties, which include strength, rigidity, toughness and ductility.

iii. Machinability or formability

\section{Material of construction of different parts of machine:}

\begin{tabular}{ll}
\hline Parts & Material Used \\
\hline Base support & Cast iron \\
Longitudinal stud & Cast iron \\
Cutting Blade & Stainless Steel \\
Clipper and Guide Pin & Stainless Steel \\
Nuts & Cast iron \\
Support legs and framework & Cast iron \\
Handle & Cast iron \\
\hline
\end{tabular}

Assumptions for stud dimensions:

Length of stud $=12$ inch

Diameter of stud $=5 / 8$ inch

Assumptions for framework dimensions:

Pipe diameter $=3 / 4$ inch

Length of pipe $=13$ inch

\section{Determination of Pitch of Stud:}

A screw works with the rotation which was provided by the handle. When the handle arm makes a full turn, the stud moved a distance equal to pitch or the gap between adjacent threads. The combination of rotary and longitudinal motion produced by handle resulted in slicing of potato. The triangular shaped pitch was made to suit the thickness of the potato slices. To provide the thickness of potato crisp $2.0 \mathrm{~mm}$, the longitudinal distance covered by the stud:

$25.4 \mathrm{~mm}=1$ inch

$2.0 \mathrm{~mm}=25.4 / 2.0=13$ threads/inch

So the pitch of the stud was 13 triangular shaped threads per inch.

\section{Dimensions of Guide Nuts:}

As given in Westermann table based on major diameter of nut

Thread size D $(\mathrm{mm})=\mathrm{M} 16$

Minor diameter $(\mathrm{mm})=13.546$

Tensile stress area (sq. $\mathrm{mm})=157$

Pitch $(\mathrm{mm})=2$

Thickness of head $(\mathrm{mm})=10$

Thickness of nut $(\mathrm{mm})=13$

Width across flats $(\mathrm{mm})=24$

Width across corners $(\mathrm{mm})=26.75$

\section{Cutting:}

Cutting involves principally the application of shearing force on potato with the help of a blade. The blade was made stationary while potato travels against it and gets sliced. Shearing force for slicing the potato was measured by placing knife of measured thickness on potato and applying mass of $1.53 \mathrm{~kg}$ which was sufficient for slicing the potato. Thus shearing Force required for cutting the potato with the help of a knife of thickness $0.0164 \mathrm{~mm}$ :

$$
\mathrm{F}_{\mathrm{s}}=1.53 \times 9.81=15 \mathrm{~N}
$$

Thickness of blade $(\mathrm{t})=0.00164 \mathrm{~mm}$

Length of blade $(\mathrm{l})=0.115 \mathrm{~mm}$

Width of blade $(\mathrm{b})=0.105 \mathrm{~mm}$

Density of blade $(\mathrm{SS})=8000 \mathrm{~kg} / \mathrm{m}^{3}$

The main components of the Twisted Potato Crisps Maker are base support, longitudinal Stud, blade, clipper, guide pin, guide Nuts, hand support, handle and Support legs.

\section{Base support:}

It was made up of cast iron. It was having a first end and a second end for providing guided linear longitudinal motion along the base. 


\section{Longitudinal Stud:}

It was having a first end and a second end, being connected at the first end whereby rotated by the handle, substantially defining a potato rotation axis. The thickness of the resulting crisp was determined by the pitch and the rate at which the potato was advanced into the blade. The combination of rotary and longitudinal motion produced due to the rotation of the stud results in slicing of potato into a continuous spiral sheet.

\section{Cutting Blade:}

A base mounted, cutting blade was provided for consistently slicing a thin continuous spiral slice. Cutting blade was made up of high carbon hardened stainless steel and was connected to the second end of the base. It was made perpendicular to potato rotational axis and had a hole through which guide pin extended to provide support for potato.

\section{Stud support:}

It was provided with a threaded cylindrical depression for receiving stud wherein stud may freely rotate and move longitudinally through depression.

\section{Clipper:}

Potato to be sliced mounted on guide pin was placed on clipper onto the second end of a stud and the potato was advanced towards a stationary blade by means of a handle. A handle was rotated in a clockwise direction turning a potato and forcing it into the blade. When the handle arm makes a full turn, the stud moved a distance equal to pitch or the gap between adjacent threads. The combination of rotary and longitudinal motion produced by handle resulted in slicing of potato. The stud was attached to the base support which has support legs to stabilize its use on a smooth surface.

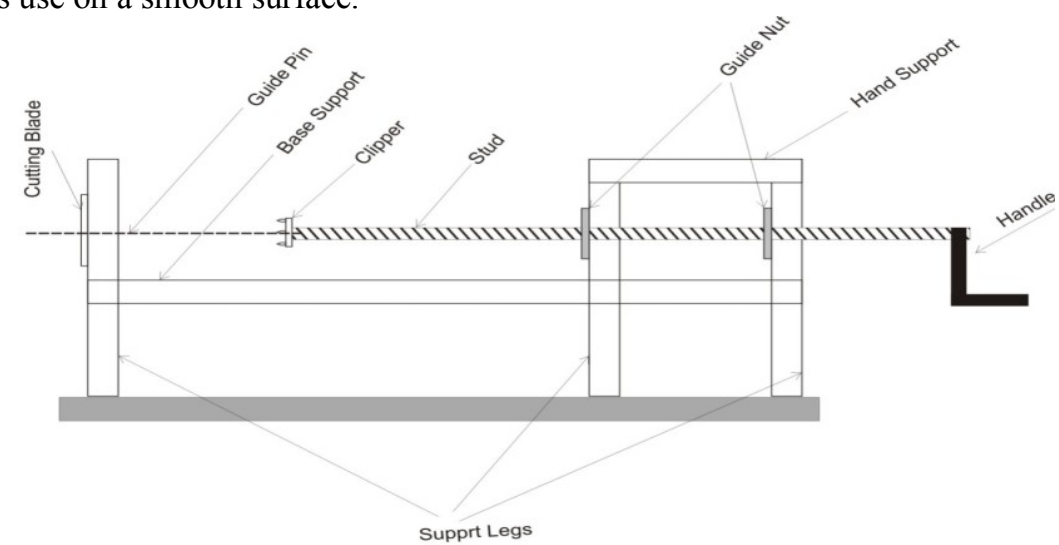

Left side view of the machine listing the component parts. Dashed lines show on the stud (drive spindle) and represent threads on the outside diameter.

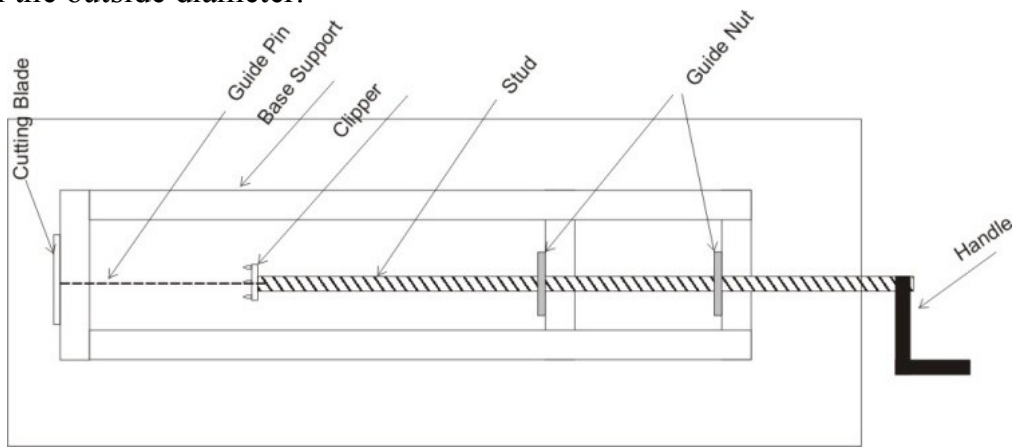

Topside view of the machine showing the component parts assembled on the top of the base support.

Performance Evaluation of the machine:-

Production capacity:

Capacity $=($ weight of potatoes sliced by the machine $) /($ time taken to slice the potatoes $)$

Product loss:

Loss $\%=$ (Difference in weight of potatoes before and after chips making) 


\section{Results and Discussion}

Efforts have been made to design and fabricate this twisted potato crisps maker. The findings have been suitably explained with logical reasons wherever possible. The findings also have been discussed in the light of theories and with the literature support to the possible extent.

\section{Fabricated Twisted Potato Crisps Maker}

The blade, stud, handle, support legs, clipper were fabricated as per their design as described earlier. The developed potato crisps maker has been shown

\section{Product Loss}

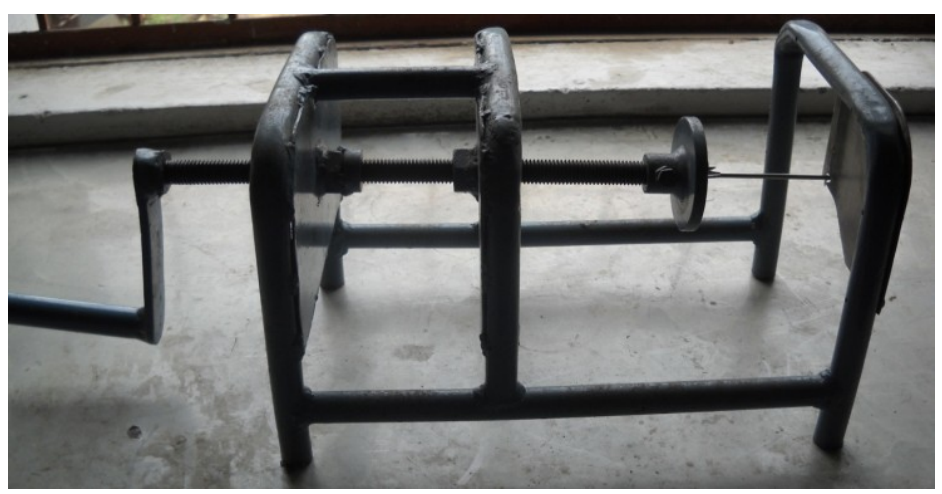

\section{Performance Evaluation of Fabricated Machine}

Product Losses were determined by taking different set of $1000 \mathrm{~g}$ of potatoes and it was found that product loss varies from $3.9 \%$ to $4.4 \%$. The average product losses were $4.067 \%$ due to stud end of potato which remains uncut and discarded.

Table 1. Product losses.

\begin{tabular}{lllll}
\hline S.No. & Initial Weight of Potatoes $\left(\mathbf{W}_{\mathbf{1}}\right)$ & Final Weight of Potatoes $\left(\mathbf{W}_{\mathbf{2}}\right)$ & Loss in Weight $\left(\mathbf{W}_{\mathbf{1}}-\mathbf{W}_{\mathbf{2}}\right)$ & $\begin{array}{l}\text { Product Loss } \\
{\left[\left(\mathbf{W}_{\mathbf{1}}-\mathbf{W}_{2}\right) / \mathbf{W} \mathbf{1} \mathbf{1 0 0}\right]}\end{array}$ \\
\hline $\mathbf{1 .}$ & $1000 \mathrm{~g}$ & $959 \mathrm{~g}$ & $41 \mathrm{~g}$ & $4.1 \%$ \\
$\mathbf{2 .}$ & $1000 \mathrm{~g}$ & $961 \mathrm{~g}$ & $39 \mathrm{~g}$ & $3.9 \%$ \\
$\mathbf{3 .}$ & $1000 \mathrm{~g}$ & $958 \mathrm{~g}$ & $42 \mathrm{~g}$ & $4.2 \%$ \\
\hline
\end{tabular}

\section{Production Capacity}

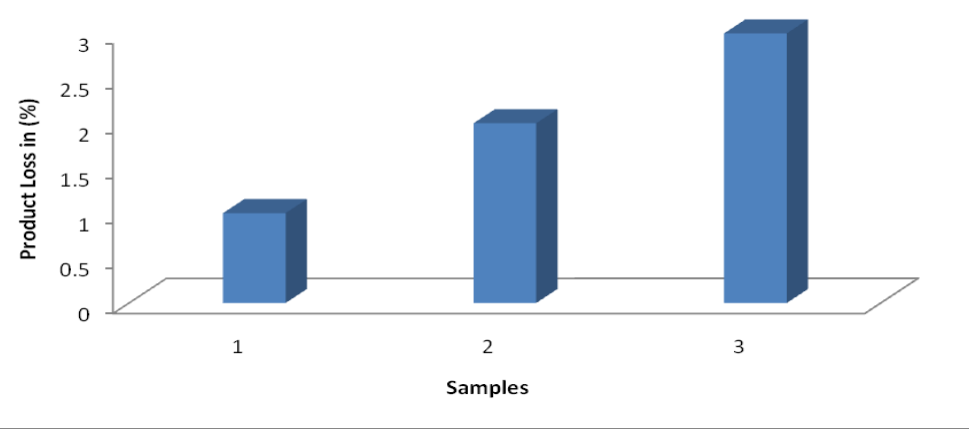

Fig.1 Product losses.

The production capacity of the fabricated machine was calculated and it was found that it varies from $9.375 \mathrm{~kg} / \mathrm{h}$ to $9.836 \mathrm{~kg} / \mathrm{h}$. The average production capacity was $9.577 \mathrm{~kg} / \mathrm{h}$.

Table 2. Production capacity of fabricated machine.

\begin{tabular}{lll}
\hline Weight of Potatoes (W) & Time Taken (T)/ Min & Production Capacity (W/T) \\
\hline $\mathbf{1 0 0 0} \mathbf{g}$ & 6.4 & $9.375 \mathrm{~kg} / \mathrm{h}$ \\
$\mathbf{1 0 0 0} \mathbf{g}$ & 6.3 & $9.52 \mathrm{~kg} / \mathrm{h}$ \\
$\mathbf{1 0 0 0} \mathbf{g}$ & 6.1 & $9.836 \mathrm{~kg} / \mathrm{h}$ \\
\hline
\end{tabular}




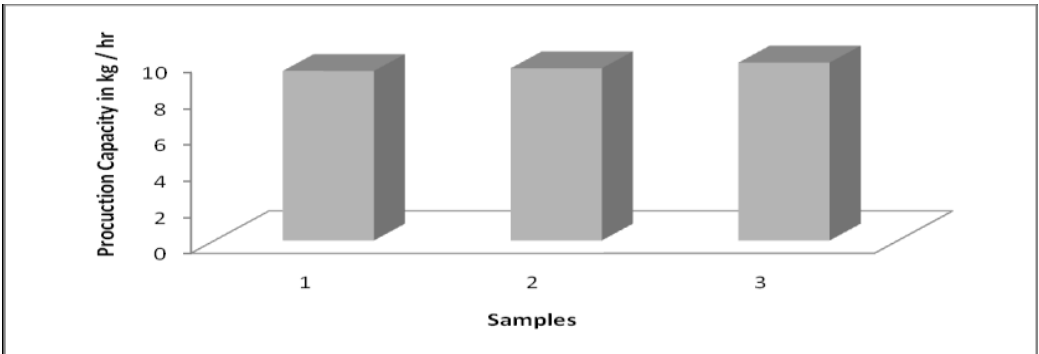

Fig. 2. Production Capacity of Fabricated Machine

\section{Conclusion}

The engineering tasks of the work have been solved. The design of the twisted potato crisps maker is based on the technical idea of the combination of rotary and longitudinal motion produced by handle, blade and the pitch of the stud provides required slice thickness. To determine the maximum shear force for potato cut into slices, we have produced the laboratory equipment. The essential constructional-designing documentation was prepared. Then, the experimental model of equipment for potato cutting into twisted slices to be implemented in the technological process was developed. The machine was conceived as laboratory level, simple to operate and easy to fabricate. This machine allows in its simplicity of design and modest cost with the ability to generate thin uniform slices utilizing approximately $95 \%$ of the potato but leaving a stub end uncut which may be discarded. The slicing efficiency obtained was $95.8-96.1 \%$ with average losses of $4.1 \%$. Capacity of machine was $9.6 \mathrm{~kg} / \mathrm{h}$ and $2.0 \mathrm{~mm}$ thickness of crisps, which meets the requirements of small scale processing unit.

\section{References}

[1]. Amaney, M.M.B., Dalia, M.M.M., Arafat M.S. (2009), Relationship between chemical composition and sensory evaluation of potato chips made from six potato varieties with emphasis on the quality on the fried sunflower oil. Journal of Dairy and Food Science; 4(2):193-200.

[2]. Baumann, B. and F. Escher, (1995), Mass and heat transfer during deep fat frying of potato slices I. Rate of drying and oil uptake. Food Science and Technology, 28: 395-403.

[3]. Dobarganes C., Marquez-Ruiz G. and Velasco J. (2000). Interaction between fat and food during deep fat frying. European Journal of Lipid Science and Technology. Vol. 6: 521-528.

[4]. FayoseF. T. (2007), Development of a cutting machine for food materials. Journal of Agricultural Engineering and Technology (JAET). Volume 15, 58-64

[5]. Felipe Richter, (2008), Influence of a blanching pretreatment on color, oil uptake and water activity of potato sticks, and its optimization. Journal of Food Process Engineering, Volume 31, pages 833-852.

[6]. George O. Abong, Michael W. Okoth, Jasper K. Imungi and Jackson N. Kabir (2011), Effect of Slice Thickness and Frying Temperature on Color, Texture and Sensory Properties of Crisps made from Four Kenyan Potato Cultivars. American Journal of Food Technology 6(9): 753-762, 2011

[7]. Grażyna Lisińska, Anna Pęksa, Agnieszka Kita, ElżbietaRytel, AgnieszkaTajner-Czopek (Poland) (2002), The Quality of Potato for Processing and Consumption 99-104.

[8]. Gunstone, R.P. (2004), Effect of temperature on selected potato chips. Department of food storage and technology, Wroclaw univ. of environmental and life sciences. Vol. 12(1):79-85.

[9]. Hall Jr. A. S, Holowenko A. R. and Laughlin H. G. (1961), Machine Design, Schanm's outline series, Mc Graw-Hill Company. New York.

[10]. Hamrock B. J., Jacobson B. and Schmid S. R, (1999), Fundamentals of Machine Elements, McGraw Hill, New York.

[11]. Hannah J. and Stephen R. C. (1974), Mechanic of Machineries Advance Theory and Examples, Edward Anold Publishing Ltd, London, 2nd Edition.

[12]. James, E. H, (1977), Engineering Design Graphics, Addison Wesley Publishing Company, Inc Philippines.

[13]. Shigley J. E. and Mischke C. R. (1989), Mechanical Engineering Design, McGraw Hill, New York.

[14]. Yildiz, A.; Koray Palazoglu, T.; Erdogdu, F. (2006), Determination of heat and mass transfer parameters during frying of potato slices. Journal of Food Engineering79 (1) 11-17

[15]. Yusuf Aminu Omeiza and Abdullahi Ibrahim (2007), Development of potato slicing machine. Continental J. Engineering Sciences 2: $49-57$ 